Polymer Journal, Vol. 2, No. 3, pp 398-406 (1971)

\title{
Copolymerization of Carbon Dioxide and $N$-Phenylethylenimine
}

\author{
Tsutomu KagiYa and Takehisa Matsuda \\ Department of Hydrocarbon Chemistry, Faculty of Engineering, \\ Kyoto University, Kyoto, Japan.
}

(Received January 21, 1971)

\begin{abstract}
ABSTRUCT: $\quad$ Carbon dioxide and $N$-phenylethylenimine were allowed to copolymerize using a Brönsted acid such as phenol or acetic acid to give a white powder, melting at $160-270^{\circ} \mathrm{C}$, with a carbon dioxide content of $2.90-20.5 \mathrm{~mol} \%$. The content of carbon dioxide in the copolymer increased with carbon dioxide in the feed, while the melting point decreased. The infrared spectrum of the copolymer showed the characteristic peak of urethane linkage. 3-Phenyl-oxazolidone-2, which might be produced by the reaction of carbon dioxide and $N$-phenylethylenimine, did not react with carbon dioxide or $N$ phenylethylenimine and was not contained in the copolymer. Carbon dioxide did not react with poly $(\mathrm{N}$-phenylethylenimine) or phenol. From the facts mentioned above, it was concluded that the formation of urethane linkage was due to the copolymerization of carbon dioxide and $N$-phenylethylenimine. From ultraviolet spectroscopic analysis of the mixture of carbon dioxide and $N$-phenylethylenimine, an appreciable interaction between two monomers was observed. From the experimental data on the monomer composition in the feed and copolymer, the apparent monomer reactivity ratios were evaluated. On the basis of these results, the probable mechanism of the copolymerization via a complex of carbon dioxide and $N$-phenylethylenimine was proposed.

KEY WARDS Carbon Dioxide / $N$-Phenylethylenimine / Copolymerization / Urethane Linkage / Complex Formation / Ultraviolet Spectrometry / Monomer Reactivity Ratio /
\end{abstract}

Since Inoue, et al., ${ }^{1}$ reported that carbon dioxide copolymerized alternatingly with alkylene oxide to give a polycarbonate, carbon dioxide cannot be regarded as an inert gas but as a monomer.

Kagiya and Narita have recently reported $^{2}$ that carbon dioxide terpolymerized with formaldehyde and $N$-phenylethylenimine. As a continuation of the terpolymerization, we studied the copolymerization of carbon dioxide with $N$-phenylethylenimine.

The purpose of this report is to study the copolymerization with weak Brönsted acid catalysts, to determine the structure of the copolymer, to evaluate the monomer reactivity ratios of these monomers, and to discuss the probable mechanism of the copolymerization on the basis of experimental results.

\section{EXPERIMENTAL}

\section{Materials}

$N$-Phenylethylenimine was prepared from $\beta$ - bromoethylaniline hydrobromide according to the literature; ${ }^{3}$ it was dried over sodium sulfate and fractionated twice before use $\left[\mathrm{bp} 70-70.5^{\circ} \mathrm{C}\right.$ $(13 \mathrm{~mm})]$. Commercial carbon dioxide was used without purification. Guaranteed reagents of acids, dimethyl carbonate and diphenyl carbonate as catalysts were used without further purification. Triethylamine was purified by the usual methods.

3-Phenyl-oxazolidone-2 was prepared according to the method reported by $\mathrm{R}$. Tsuzuki, et al., ${ }^{4}$ from ethylene carbonate and phenyl isocyanate with $N$-methylmorpholine catalyst. Crude material was further purified by recrystallization from ethanol. The melting point was 118$119^{\circ} \mathrm{C}$ (lit. ${ }^{4} 117-119^{\circ} \mathrm{C}$ ).

Anal. Calcd for $\mathrm{C}_{9} \mathrm{H}_{9} \mathrm{NO}: \mathrm{C}, 66.21 ; \mathrm{N}, 8.56$. Found : C, 66.18; N, 8.53.

\section{Polymerization Procedure}

A $30-\mathrm{m} l$ stainless steel autoclave was used as the reaction vessel. The vessel was degassed in vacuo and cooled at $-78^{\circ} \mathrm{C}$. Measured quantities 


\section{Copolymerization of Carbon Dioxide and Imine}

of the catalyst and $N$-phenylethylenimine were placed in the autoclave, and then carbon dioxide was introduced. The vessel was kept standing in an oil bath for five hours at $100 \pm 1{ }^{\circ} \mathrm{C}$. After the reaction, the unused carbon dioxide was removed, and the polymer was washed with cooled diethyl ether and ethanol, dried in vacuo at room temperature, and weighed. Occasionally the polymer was dissolved in formic acid, and then reprecipitated from hot ethanol.

\section{Physical Analyses of the Copolymer}

The composition of the copolymer was determined by elemental analysis. The melting point of the copolymer was measured visually under a nitrogen atmosphere in a capillary with a Yanagimoto melting point measuring apparatus, Model MP-S2, equipped with a microscope $(\times 10)$. The infrared spectrum was obtained with the use of the potassium bromide pellet technique on a JASCO Grating Infrared Spectrometer, Model DS-403G. The specific viscosity of a $0.25-\%$ solution in $90-\%$ formic acid was measured at $35^{\circ} \mathrm{C}$ with an Ubbelohdetype viscometer. Thermal gravimetric analysis (TGA) in nitrogen was measured with a du Pont-T-900 using $2-5 \mathrm{mg}$ of sample at the rate of $10^{\circ} \mathrm{C} / \mathrm{min}$. The $\mathrm{X}$-ray diffraction diagram was recorded with a powder camera on a Shimazu X-ray diffractometer, Model GX-3B.

The ultraviolet spectrum of the mixture of carbon dioxide and $N$-phenylethylenimine was

Table 1. Copolymerization of carbon dioxide and $\mathrm{N}$-phenylethylenimine

\begin{tabular}{|c|c|c|c|c|c|c|c|c|c|c|}
\hline $\begin{array}{l}\text { Run } \\
\text { no. }\end{array}$ & $\begin{array}{c}N \text {-Phenyl- } \\
\text { ethylen- } \\
\text { imine, } \\
\mathrm{g}\end{array}$ & $\begin{array}{l}\text { Carbon } \\
\text { dioxide, } \\
\mathrm{g}\end{array}$ & $\begin{array}{l}\text { Other } \\
\text { reactants, } \\
\text { g }\end{array}$ & Catalyst & $\begin{array}{c}\text { Reaction } \\
\text { tempera- } \\
\text { ture, } \\
{ }^{\circ} \mathrm{C}\end{array}$ & $\begin{array}{l}\text { Yield, } \\
\text { mg }\end{array}$ & $\begin{array}{l}\text { Melting } \\
\text { point, } \\
{ }^{\circ} \mathrm{C}\end{array}$ & $\eta_{\mathrm{sp}} / c^{\theta}$ & U. L.g & $\begin{array}{l}f_{\mathrm{CO}_{2}}{ }^{\mathrm{f}} \\
\times 10^{2}\end{array}$ \\
\hline 1 & 2.00 & - & - & Phenol $^{\mathrm{b}}$ & 100 & 312 & 286 & 0.20 & $x$ & - \\
\hline 2 & 2.00 & - & - & - & 100 & 0 & - & - & - & - \\
\hline 3 & 2.00 & 10.00 & - & $\begin{array}{l}\text { Acetic }^{b} \\
\text { acid }\end{array}$ & 100 & 215 & 165 & 0.20 & 0 & - \\
\hline 4 & 2.00 & 25.06 & - & Phenol $^{\mathrm{b}}$ & 100 & 280 & 160 & 0.21 & 0 & 20.5 \\
\hline 5 & 2.00 & 0.73 & - & Phenol $^{b}$ & 100 & 254 & 268 & 0.20 & 0 & 2.9 \\
\hline 6 & 2.00 & 0.75 & - & $\begin{array}{l}\text { Acetic }{ }^{b} \\
\text { acid }\end{array}$ & 100 & 201 & 270 & 0.18 & 0 & - \\
\hline 7 & 2.00 & - & $\begin{array}{l}\mathrm{Ox}^{\mathrm{h}} \\
3.00\end{array}$ & Phenol $^{\mathrm{c}}$ & 130 & 467 & 285 & 0.19 & $x$ & - \\
\hline 8 & - & - & $\begin{array}{l}\mathrm{Ox}^{\mathrm{h}} \\
3.00\end{array}$ & $\mathrm{TEA}^{\mathrm{c}}$ & 130 & 0 & - & - & - & - \\
\hline 9 & - & - & $\begin{array}{l}O x^{h} \\
3.00\end{array}$ & Phenol $^{\mathrm{c}}$ & 130 & 0 & - & - & - & - \\
\hline 10 & - & 10.00 & $\begin{array}{l}\mathrm{PEI}^{\mathrm{i}} \\
0.582\end{array}$ & Phenol $^{\mathrm{d}}$ & 100 & 561 & 286 & - & $x$ & - \\
\hline 11 & - & 10.04 & $\begin{array}{l}\mathrm{PEI}^{\mathrm{i}} \\
0.462\end{array}$ & TEA $^{d}$ & 100 & 445 & 286 & - & $x$ & - \\
\hline 12 & 2.00 & - & - & $\begin{array}{l}\text { Dimethyl }{ }^{\mathrm{b}} \\
\text { carbonate }\end{array}$ & 100 & 0 & - & - & - & - \\
\hline 13 & 2.00 & - & - & $\begin{array}{l}\text { Diphenylb } \\
\text { carbonate }\end{array}$ & 100 & 0 & - & - & - & - \\
\hline
\end{tabular}

a Polymerizations were carried out in an autoclave for five hours.

b Catalyst $/ N$-phenylethylenimine $=1.5 / 1000$ (molar ratio).

c Triethylamine (TEA) or phenol/3-phenyl-oxazolidone-2=1.5/1000 (molar ratio).

d Triethylamine (TEA) or phenol/poly $(N$-phenylethylenimine) $=1.5 / 1000$ (molar ratio).

- The specific viscosities of $0.25-\%$ solution of $90-\%$ formic acid at $35^{\circ} \mathrm{C}$.

f Calculated from elemental analysis (see Table II).

$\mathrm{g}$ The characteristic absorption of urethane linkage in the infrared spectrum of the copolymer.

h 3-Phenyl-oxazolidone-2 (Ox).

i $\operatorname{Poly}(N$-phenylethylenimine) (PEI). 


\section{T. Kagiya and T. Matsuda}

measured with the use of a quartz cell specially designed for measurement under high pressure. A drop of liquid $N$-phenylethylenimine was placed in the cell, evacuated in vacuo, and then carbon dioxide was introduced in to the cell. A Perkin-Elmer Model 302 was used to measure the ultraviolet spectrum.

\section{Hydrolysis of the Copolymer}

The hydrolysis of the copolymer shown at run no. 3 in Table I was carried out in formic acid at $60^{\circ} \mathrm{C}$ for seven hours. The reaction product was precipitated from hot ethanol, and washed with dry diethyl ether.

\section{RESULTS AND DISCUSSION}

\section{Polymer Structure and Reaction Routes}

The results are summarized in Tables I and II.

Table II. Copolymerization of carbon dioxide and $N$-phenylethylenimine with phenol catalyst ${ }^{a}$

\begin{tabular}{|c|c|c|c|c|c|c|}
\hline $\begin{array}{c}\text { Run } \\
\text { no. }\end{array}$ & $\begin{array}{c}\mathrm{CO}_{2} \\
\text { in the feed } \\
\mathrm{g}\end{array}$ & $\begin{array}{l}\mathrm{CO}_{2} / \mathrm{EI} \\
\text { molar ratio }\end{array}$ & $\begin{array}{l}\text { Yield, } \\
\text { mg }\end{array}$ & $\underset{{ }^{\circ} \mathrm{C}}{\mathrm{mp}}$ & $\begin{array}{c}f_{\mathrm{CO}_{2}},{ }^{\mathrm{c}} \\
\times 10^{2}\end{array}$ & $\underset{\times 10^{2}}{f_{\mathrm{u}}{ }^{\mathrm{d}}}$ \\
\hline 1 & 0.13 & 1.01 & 207 & 268 & 2. & 3.00 \\
\hline 2 & 1.60 & 2.21 & 283 & 258 & 5.30 & 5.61 \\
\hline 3 & 3.53 & 5.02 & 275 & 245 & 11.1 & 12.5 \\
\hline 4 & 7.29 & 10.03 & 290 & 178 & 14.5 & 17.0 \\
\hline 5 & 19.60 & 27.11 & 297 & 165 & 18.6 & 22.8 \\
\hline 6 & 25.06 & 34.52 & 280 & 160 & 20.5 & 25.8 \\
\hline
\end{tabular}

a Polymerization conditions: $100^{\circ} \mathrm{C} ; 5 \mathrm{hr}$; phenol catalyst, $2.52 \times 10^{-5} \mathrm{~mol}(0.15 \mathrm{~mol} \%$ to $N$-phenylethylenimine).

${ }^{b} \mathrm{~N}$-phenylethylenimine (EI), $2.00 \mathrm{~g}\left(1.680 \times 10^{-2}\right.$ mol).

c $f_{\mathrm{CO}_{2}}$ is the content of carbon dioxide in the copolymer.

a $f_{\mathrm{u}}$ is the content of the urethane in the copolymer.

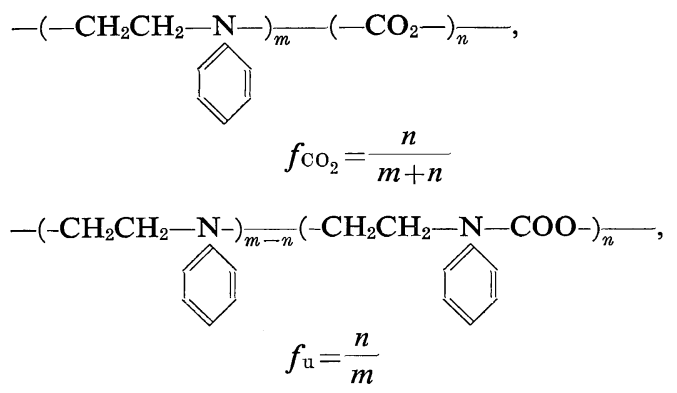

As shown under run no. 1 in Table I, $N$-phenylethylenimine polymerized with phenol catalyst to give a white crystalline polymer melting at $286^{\circ} \mathrm{C}$. $N$-Phenylethylenimine and carbon dioxide give a polymer in the presence of weak Brönsted acids such as acetic acid or phenol, but give no polymer in the absence of the catalyst, as shown under run no. $2-4$ in Table I. The polymer obtained here was a white powdery solid soluble in formic acid and $N, N$-dimethylacetamide, but insoluble in ethanol, chloroform, diethyl ether, and other common organic solvents.

As is indicated in Figure 1, the infrared spectra of the polymers are similar to that of poly $(N$-phenylethylenimine) obtained with phenol catalyst, and exhibit absorption at 1600 and $1500 \mathrm{~cm}^{-1}$ based on the benzene nucleus, and display a new characteristic absorption peak at $1725-1730 \mathrm{~cm}^{-1}$. This absorption band is similar to that of poly $(N$-phenylcarbamate $)$ $\left(1720 \mathrm{~cm}^{-1}\right)^{5}$. Accordingly, this characteristic absorption is attributable to urethane linkage. The relative intensity ratio of the characteristic absorption assignable to urethane linkage to the absorption bands of mono-substituted benzene

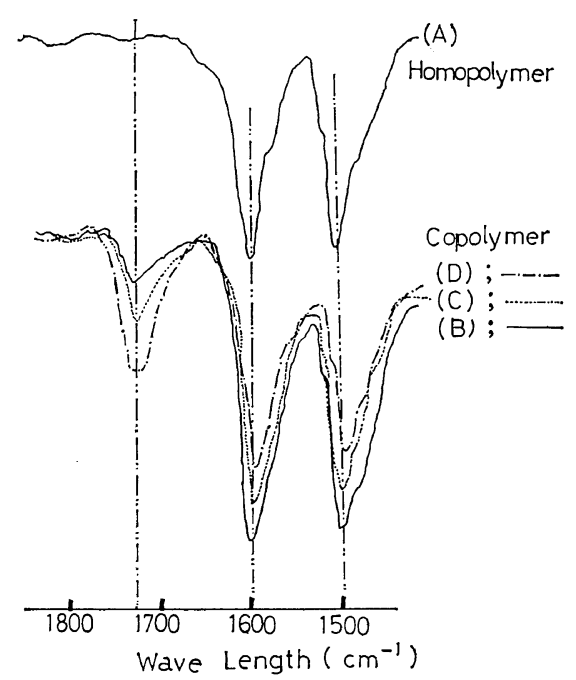

Figure 1. Infrared spectra of the copolymers of carbon dioxide and $N$-phenylethylenimine: (A), poly( $N$-phenylethylenimine); (B), (C), and (D), copolymers shown under run no. 1,3 , and 4 in Table II, respectively. (Carbon dioxide content: (B), $2.9 \mathrm{~mol} \%$; (C), $11.1 \mathrm{~mol} \%$; (D), $14.5 \mathrm{~mol} \%$ ). 
ring increased with an increase in the content of carbon dioxide in the polymer.

On the other hand, the melting point of the polymer decreased with an increase in the content of carbon dioxide in the feed (Table I and Figure 2). The specific viscosities in formic acid solution of the resulting polymers are similar to that of poly( $N$-phenylethylenimine), independent of the content of carbon dioxide in the copolymer, as shown in Table I. However, the specific viscosity of the polymer (run no. 3 in the Table I) hydrolyzed in formic acid solution at $60^{\circ} \mathrm{C}$ was reduced to nearly one sixth of that of the original polymer $\left[\eta_{\mathrm{sp}} / c=0.20\right.$ (original)-0.03(hydrolyzed]. Furthermore, as shown at run no. 10 and 11 in Table $I$, carbon dioxide did not react with $\operatorname{poly}(N$-phenylethylenimine) or phenol.

On the basis of these results, the following reaction scheme could be considered as possible reaction routes to form the urethane linkage. That is, path (1) is the direct copolymerization, and path (2) the cyclization reaction gives the cyclic urethane compound(3-phenyl-oxazolidone2). paths (3) and (4) are the homopolymerization and copolymerization with $N$-phenylethylenimine, respectively. The polymer obtained here could possibly be the copolymer (A) through path (1) or path (3), a mixture of $\operatorname{poly}(N$-phenylethylenimine $)(\mathrm{C})$ and the cyclic compound (B) or a mixture of the homopolymer(C) and poly$(N$-phenylcarbamate)(D).

The X-ray diffraction diagram of the polymer shows no characteristic peaks of 3-phenyloxazolidone- $2(2 \theta=20.7,23.1$ and 27.4). The resulting polymer was fractionated in hot ethanol, which was a good solvent for only 3-phenyl-oxazolidone-2. The infrared spectrum of the insoluble fraction in hot ethanol was identical with the original polymer. On the other hand, the infrared spectrum of the insoluble fraction of the mixture of poly $(N$-phenylethylenimine) and 3-phenyl-oxazolidone-2 [15 wt $\%$ to $\operatorname{poly}(N$-phenylethylenimine $)]$ displayed no characteristic absorption of 3-phenyl-oxazolidone2 ascribed to urethane linkage $\left(1735 \mathrm{~cm}^{-1}\right)$. Furthermore, as shown under run no. 7-9 in Table I, 3-phenyl-oxazolidone-2 did not polymerize with $N$-phenylethylenimine by triethyl amine or phenol catalyst, and this cyclic derivative was recovered quantitatively: These facts indicate that 3-phenyl-oxazolidone-2 was not formed by the reaction of carbon dioxide and $N$-phenylethylenimine during the copolymerization. These results may lead to the conclusion that the copolymer of carbon dioxide and $N$ phenylethylenimine was formed by the copolymerization of two monomers [path (1)] to produce urethane linkage

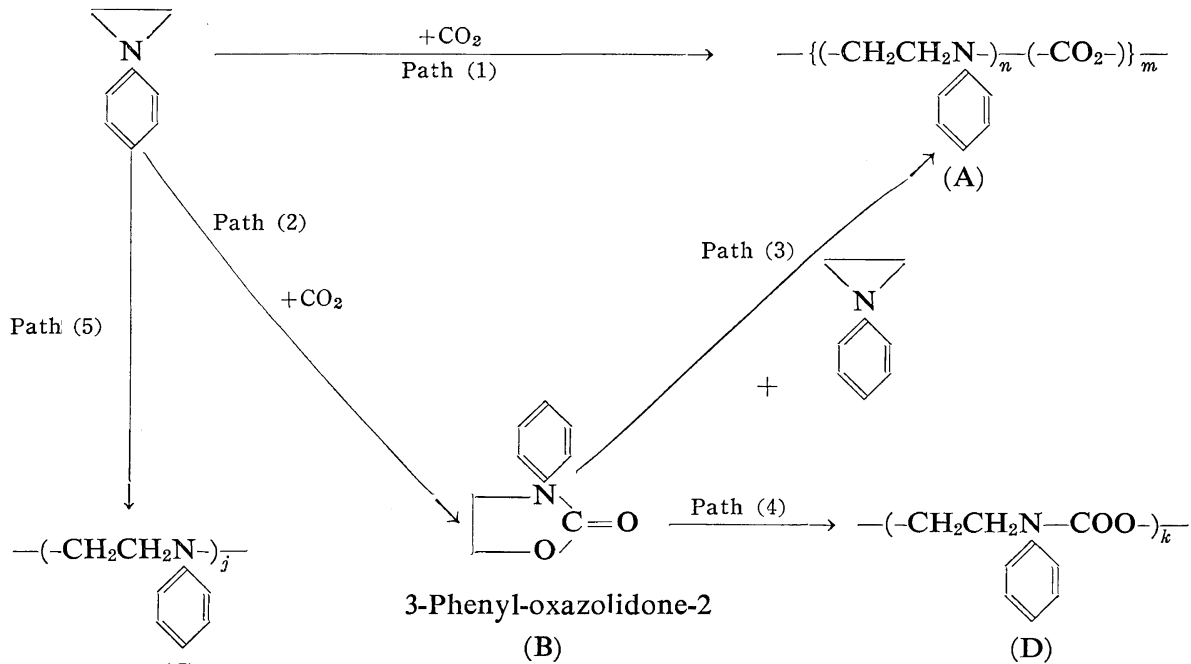

(C)

(D) 


\section{T. Kagiya and T. Matsuda}

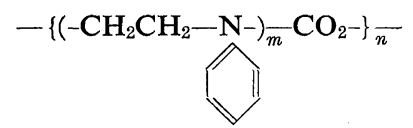

or

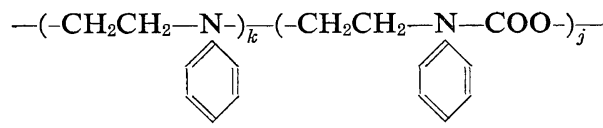

Influence of the Monomer Composition on the Copolymerization

The influence of the monomer composition on the copolymerization with phenol catalyst at $100^{\circ} \mathrm{C}$ was investigated. The results are shown in Table II. The content of the urethane linkage in the copolymer is plotted against the

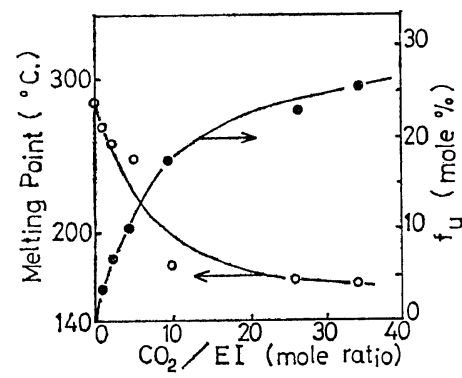

Figure 2. Variations in the urethane content and melting points of the copolymer, with changes in monomer feed ratio: $f_{\mathrm{u}}$, the urethane content in the copolymer; EI, $N$-phenylethylenimine.

initial monomer mixture (Figure 2). With an increase in the concentration of carbon dioxide in the feed, the urethane content in the resulting copolymer increased to $25.8 \mathrm{~mol} \%$.

\section{Thermal Properties of the Copolymer}

As shown in Figure 2, the melting point of the resulting copolymer decreased abruptly with an increase in the content of carbon dioxide in the copolymer, and it reached nearly $160^{\circ} \mathrm{C}$ under experimental conditions. In addition, it has been reported that 2- $N$-phenylimino-1, 3dioxolane polymerizes with various Lewis acid catalysts to give poly(ethylene- $N$-phenylcarbamate $),-\left(-\mathrm{CH}_{2} \mathrm{CH}_{2}-\mathrm{N}-\mathrm{COO}-\right)_{\bar{n}}$, melting at

$170-190^{\circ} \mathrm{C}^{5,6}$
A typical thermal degradation curve of the copolymer in run no. 4 in Table $I$ in a nitrogen atmosphere is shown in Figure 3. This

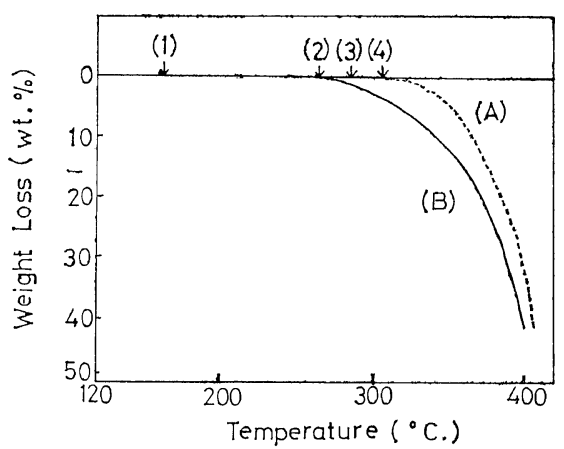

Figure 3. Thermogravimetric curve of the copolymer and poly( $N$-phenylethylenimine): (A), poly( $N$-phenylethylenimine) (PEI); (B), copolymer of carbon dioxide and $N$-phenylethylenimine (run no. 4 in Table I); (1), melting point of copolymer, $165^{\circ} \mathrm{C}$; (2), decomposition point of copolymer, $264^{\circ} \mathrm{C}$; (3), melting point of PEI, $286^{\circ} \mathrm{C}$; (4), decomposition point of $\mathrm{PEI}, 305^{\circ} \mathrm{C}$.

copolymer melted at $165^{\circ} \mathrm{C}$ and began to decompose at $264^{\circ} \mathrm{C}$. No volatile fraction of the copolymer was observed. On the other hand, poly $(N$-phenylethylenimine $)$ melted at $286^{\circ} \mathrm{C}$ and immediately began to decompose. The results indicate that the copolymer exhibits a lower melting point and a higher thermal stability compared with poly( $N$-phenylethylenimine).

Ultraviolet Spectroscopic Analysis of the Mixture of Carbon Dioxide and N-Phenylethylenimine

In order to elucidate the mechanism of the copolymerization, the ultraviolet spectrum of the mixture of carbon dioxide and $N$-phenylethylenimine was measured. $N$-Phenylethylenimine displayed the characteristic absorption at $2700 \AA$, while carbon dioxide has no absorption in the range of the neighbourhood of $2700 \AA$, as shown in Figure 4. This characteristic absorption peak of $N$-phenylethylenimine shifted towards a longer wave length, with an increase in the pressure of carbon dioxide, while the intensity and the shape of the characteristic peak became stronger and sharper, respectively. In view of the above observation, it seems reasonable to assume the formation of the 


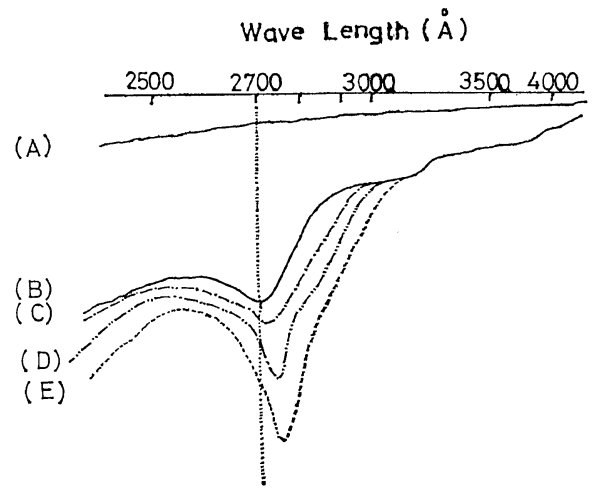

Figure 4. Ultraviolet spectra of the mixture of carbon dioxide and $N$-phenylethylenimine: (A), carbon dioxide, $2.3 \mathrm{~g}\left(55 \mathrm{~kg} / \mathrm{cm}^{2}\right)$; (B), $N$-phenylethylenimine; (C), (D) and (E), the mixture of carbon dioxide and $N$-phenylethylenimine.

Carbon dioxide pressure: (C), $0.5 \mathrm{~g}\left(12 \mathrm{~kg} / \mathrm{cm}^{2}\right)$; (D), $1.4 \mathrm{~g}\left(35 \mathrm{~kg} / \mathrm{cm}^{2}\right)$; (E), $1.9 \mathrm{~g}\left(45 \mathrm{~kg} / \mathrm{cm}^{2}\right)$. The quartz cell used for measurement was about $2.4 \mathrm{~cm}^{3}$ in volume. Carbon dioxide was charged to one drop of $N$-phenylethylenimine $(c a .0 .020 \mathrm{~g}$ ).

complex between carbon dioxide and $N$-phenylethylenimine. This complex would be caused by the donor acceptor interaction between basic $N$-phenylethylenimine and acidic carbon dioxide and may contribute to the formation of urethane linkage in the transition state of the propagation reaction.

\section{Mechanism of the Copolymerization}

The following mechanism has been proposed for the initiation and propagation of the homopolymerization of $\mathrm{N}$-phenylethylenimine catalyzed with weak Brönsted acids (HX). ${ }^{7}$

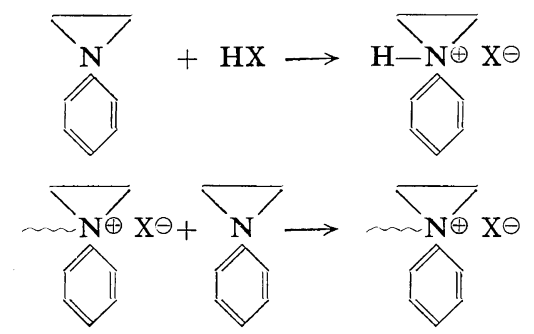

Two different mechanisms may be considered for the cross-propagation in which carbon dioxide is incorporated into the polymer.
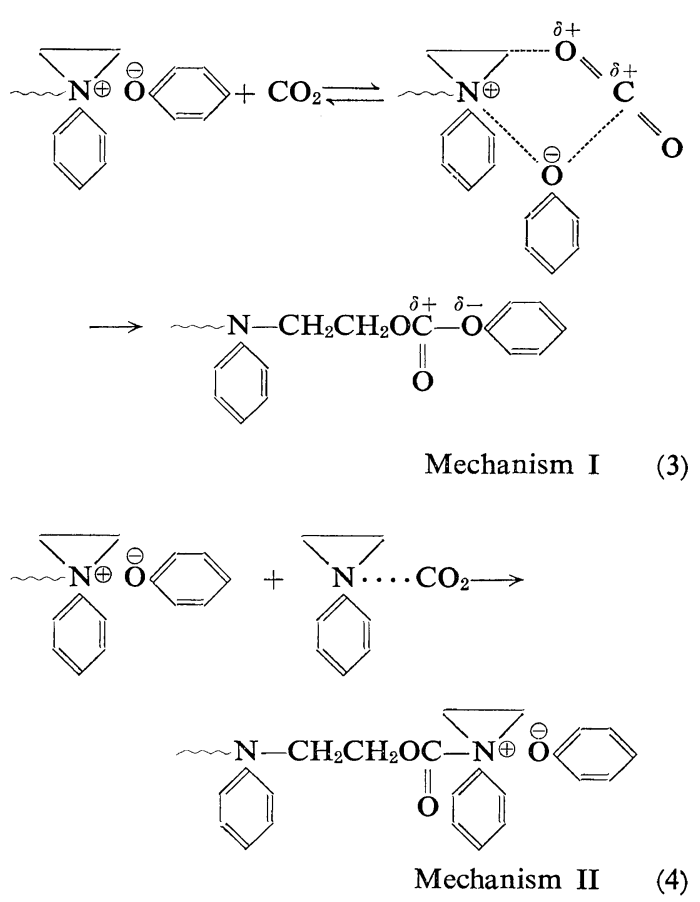

In mechanism I, free carbon dioxide reacts with the propagating species to form the carbonate linkage which may be partially ionized. On the other hand, by assuming an equimolar complex of carbon dioxide and $N$-phenylethylenimine, the incorporation of carbon dioxide into the polymer chain can be explained by mechanism II as eq 4.

In order to determine the mechanism, the polymerization of $\mathrm{N}$-phenylethylenimine was attempted with dimethyl carbonate or diphenyl carbonate catalyst. According to mechanism I, the structure of the chain end is similar to that of the active propagating chain end in the polymerization.

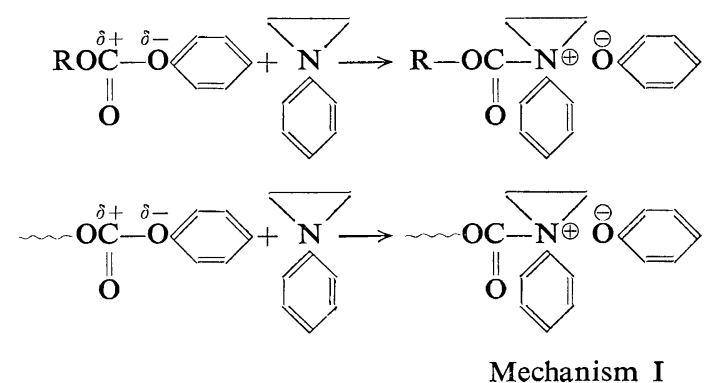


However no polymer was obtained, as shown in run no. 12 and 13 in Table I. From these results, the possibility of mechanism I may be ignored.

In mechanism II, the terminal immonium ion can react either with equimolar complex of carbon dioxide and $N$-phenylethylenimine, or with $N$-phenylethylenimine. Furthermore, the result of the ultraviolet measurements is consistent with the mechanism II. It may be considered that the urethane linkage in the copolymer is formed by the insertion of the complex to the propagating species of immonium ion through the seven-membered transition state as follows.
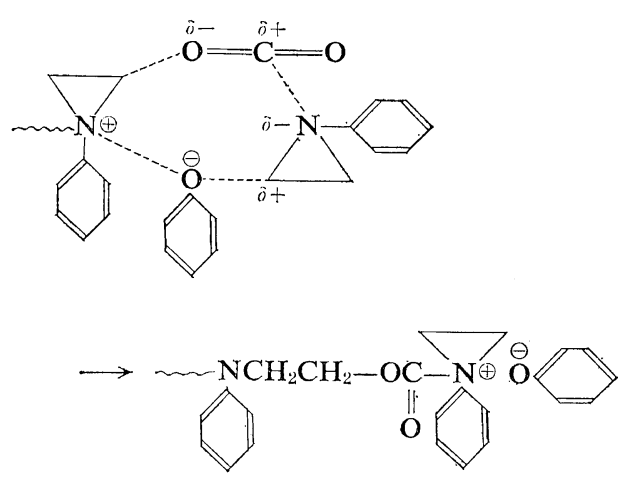

The ionic character of carbon dioxide would be enhanced by the complex formation with $N$ phenylethylenimine. The enhanced reactivity of carbon dioxide to the propagating immonium ion may then contribute to the formation of the urethane linkage.

\section{Monomer Reactivity in the Copolymerization}

From the above discussion, it is suggested that the progagation reaction in this copolymerization is composed of two competitive reactions of eq 2 and 4 . Consequently, the rates of consumption of the two monomers are expressed by the following equations

$$
\begin{aligned}
& -\frac{\mathrm{d}[\mathrm{N}]}{\mathrm{d} t}=k_{\mathrm{NN}}\left[\mathrm{N}^{+}\right][\mathrm{N}]+k_{\mathrm{UN}}\left[\mathrm{U}^{+}\right][\mathrm{N}] \\
& -\frac{\mathrm{d}[\mathrm{U}]}{\mathrm{d} t}=k_{\mathrm{UU}}\left[\mathrm{U}^{+}\right][\mathrm{U}]+k_{\mathrm{NU}}\left[\mathrm{N}^{+}\right][\mathrm{U}]
\end{aligned}
$$

where $\mathrm{N}$ and $\mathrm{U}$ denote free $N$-phenylethylenimine and the equimolar complex of carbon dioxide and $N$-phenylethylenimine, respectively, $\mathrm{N}^{+}$and $\mathrm{U}^{+}$the active propagating species of

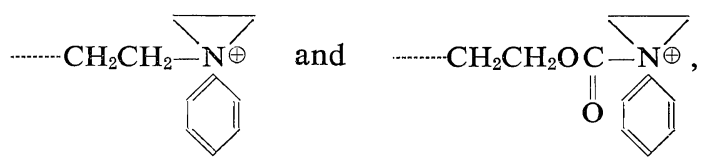

$k_{\mathrm{NN}}, k_{\mathrm{NU}}, k_{\mathrm{UU}}$ and $k_{\mathrm{UN}}$ rate constants of the propagation reaction as shown in eq 5 and 6 .

Accordingly, the differential copolymer equation is given as

$$
\frac{\mathrm{d}[\mathrm{N}]}{\mathrm{d}[\mathrm{U}]}=\frac{k_{\mathrm{NN}}\left[\mathrm{N}^{+}\right]+k_{\mathrm{UN}}\left[\mathrm{U}^{+}\right]}{k_{\mathrm{UU}}\left[\mathrm{U}^{+}\right]+k_{\mathrm{UN}}\left[\mathrm{N}^{+}\right]} \cdot \frac{[\mathrm{N}]}{[\mathrm{U}]}
$$

and the equation of Fineman-Ross is obtained easily as follows

$$
\frac{F(f-1)}{f}=\frac{k_{\mathrm{NN}}}{k_{\mathrm{NU}}} \cdot \frac{F^{2}}{f}-\frac{k_{\mathrm{UU}}}{k_{\mathrm{UN}}}
$$

where $f=\mathrm{d}[\mathrm{N}] / \mathrm{d}[\mathrm{U}]$ and $F=] \mathrm{N}] /[\mathrm{U}]$ denote the molar ratio of free $N$-phenylethylemine to the complex in the copolymer and in the initial monomer mixture, respectively.

If the equilibrium of the complex formation is established according to the eq 9

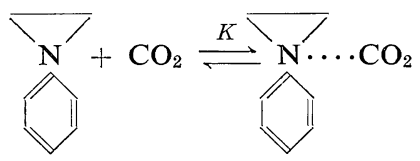

then the equilibrium constant of the complexation, $K$, is given by

$$
K=\frac{[\text { Complex }]}{[\mathrm{N}]\left[\mathrm{CO}_{2}\right]_{s o l}}
$$

where $\left[\mathrm{CO}_{2}\right]_{s o l}$ is the concentration of free carbon dioxide in the solution.

Accordingly

$$
[\text { Complex }]=\frac{K\left[\mathrm{CO}_{2}\right]_{s o l}[\mathrm{~N}]_{m}}{1+K\left[\mathrm{CO}_{2}\right]_{s o l}}
$$

where $[\mathrm{N}]_{m}$ is the total concentration of free and complexed $N$-phenylethylenimine in the solution.

If $K \ll 1$

$$
[\text { Complex }]=K\left[\mathrm{CO}_{2}\right]_{s o l}[\mathrm{~N}]_{m}
$$

If the dissolution of carbon dioxide in $\mathrm{N}$ phenylethylenimine obeys Henry's law under the reaction conditions, the following can be obtained. 


$$
\begin{aligned}
& \mathrm{CO}_{2 s o l} \stackrel{K_{s}}{\rightleftharpoons} \mathrm{CO}_{2 g a s} \\
& {\left[\mathrm{CO}_{2}\right]_{s o l}=K_{\mathrm{s}}\left[\mathrm{CO}_{2}\right]_{g}[\mathrm{~N}]_{m}}
\end{aligned}
$$

where $K_{\mathrm{s}}$ designates the solubility constant of carbon dioxide in $N$-phenylethylenimine and $\left[\mathrm{CO}_{2}\right]_{g}$ the amount of carbon dioxide in gaseous phase.

From eq 11 and $12, F$ is given by

$$
F=\frac{1}{K K_{s}\left[\mathrm{CO}_{2}\right]_{g}[\mathrm{~N}]_{m}}
$$

Under the conditions of low conversion and high reaction temperature,

$$
\left[\mathrm{CO}_{2}\right]_{g} \simeq\left[\mathrm{CO}_{2}\right]_{0} \text { and }[\mathrm{N}]_{m} \simeq[\mathrm{N}]_{0}
$$

where $\left[\mathrm{CO}_{2}\right]_{0}$ and $[\mathrm{N}]_{0}$ denote the initial concentration of carbon dioxide and $N$-phenylethylenimine, respectively.

Consequently, using eq 8 and 13 , the Fineman-Ross equation would be given as the following.

$$
\frac{f-1}{f\left[\mathrm{CO}_{2}\right]_{0}[\mathrm{~N}]_{0}}=\frac{k_{\mathrm{NN}}}{K K_{s} k_{\mathrm{NU}}} \frac{1}{f\left[\mathrm{CO}_{2}\right]_{0}{ }^{2}[\mathrm{~N}]_{0}{ }^{2}}-\frac{k_{\mathrm{UU}} K K_{s}}{k_{\mathrm{UN}}}
$$

The plot of the left hand side of eq 14 against the reciprocal of $f\left[\mathrm{CO}_{2}\right]_{0}^{2}[\mathrm{~N}]_{0}^{2}$ gives a fairly straight line through the origin as shown in Figure 5. From the slope and intercept of the straight line, we obtained the following apparent monomer reactivity ratios

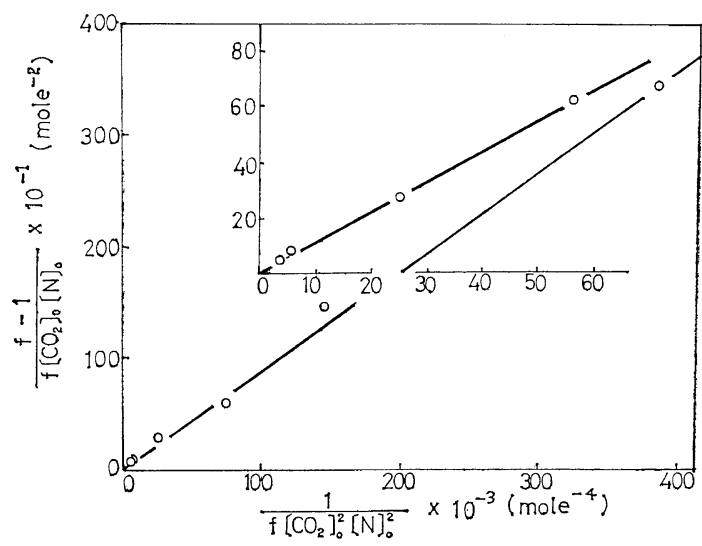

Figure 5. Plot of $(f-1) / f\left[\mathrm{CO}_{2}\right]_{0}[\mathrm{~N}]_{0}$ against the reciprocal of $f\left[\mathrm{CO}_{2}\right]_{0}^{2}[\mathrm{~N}]_{0}^{2}$.

Reaction conditions are the same as for Table II.

$$
\begin{array}{ll}
\frac{k_{\mathrm{NN}}}{k_{\mathrm{NU}} K K_{s}}=9 \times 10^{-3} & \left(\mathrm{~mol}^{2} l^{-2}\right) \\
\frac{k_{\mathrm{UU}} K K_{s}}{k_{\mathrm{UN}}}=0 & \left(\mathrm{~mol}^{-2} l^{2}\right)
\end{array}
$$

Substituting these values in eq 7 on the steadystate assumption, we obtained

$$
\frac{\mathrm{d}[\mathrm{N}]}{\mathrm{d}[\mathrm{U}]}=\frac{9 \times 10^{-3}}{\left[\mathrm{CO}_{2}\right]_{0}[\mathrm{~N}]_{0}}+1
$$

Accordingly, the urethane content in the copolymer, $f_{\mathrm{u}}$, would be expressed as follows.

$$
\frac{1}{f_{\mathrm{u}}}=\frac{\mathrm{d}[\mathrm{N}]+\mathrm{d}[\mathrm{U}]}{\mathrm{d}[\mathrm{U}]}=\frac{9 \times 10^{-3}}{\left[\mathrm{CO}_{2}\right]_{0}[\mathrm{~N}]_{0}}+2
$$

The reciprocal plot of the observed urethane content in the copolymer against the product of the concentrations of two monomers in the initial monomer mixture gives a fairly straight line, as is indicated in Figure 6. The distinct linear relation almost coincides with the calculated straight line according to eq 17 . Consequently, from the intercept of this straight line, it is expected that the maximum urethane content in the copolymer would reach $50 \mathrm{~mol} \%$. These results are consistent with the previous reaction scheme that the consumption reaction of carbon dioxide occurs through an equimolar complex of two monomers. In the mechanism

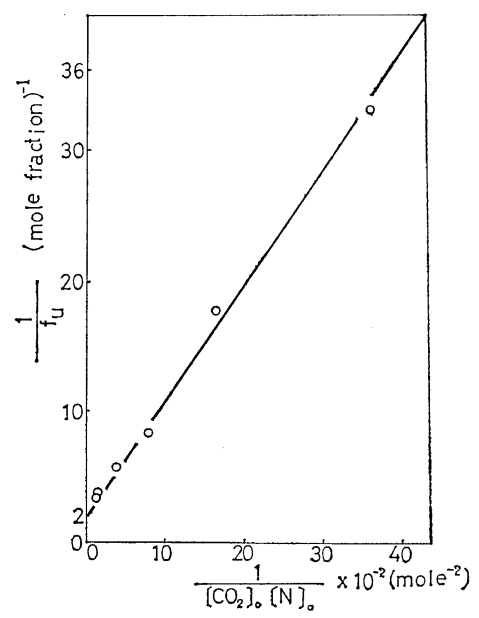

Figure 6. Relation between the urethane content in the copolymer and carbon dioxide content in the initial monomer mixture.

Reaction conditions are the same as for Table II. The full line is calculated from eq 17. 
that the copolymerization proceeds via a $2: 1$ complex of carbon dioxide with $N$-phenylethylenimine, the theoretical maximum urethane content in the copolymer was calculated as $\mathbf{3 3 . 3}$ mol $\%$ in a similar manner. Therefore, it is considered that the complex composition is an equimolar complex of two monomers rather than a $2: 1$ complex.

On the other hand, if this copolymerization proceeds via mechanism I, the following copolymer-composition equation is easily obtained on refering to eq 17

$$
\frac{1}{f_{\mathrm{CO}_{2}}}=-\frac{k_{\mathrm{NN}}}{K_{s} k_{\mathrm{NC}}\left[\mathrm{CO}_{2}\right]_{0}[\mathrm{~N}]_{0}}+2
$$

where $f_{\mathrm{CO}_{2}}$ is the content of carbon dioxide in the copolymer, $k_{\mathrm{NC}}$ the rate constant of the propagation reaction according to eq 3 , and $k_{\mathrm{CC}}$ is the rate constant of addition reaction of carbon dioxide to the propagating carbonate chain-end and is negligibly small considering that a homopolymer of carbon dioxide is unknown. The relation between $f_{\mathrm{CO}_{2}}$ and $f_{\mathrm{u}}$ is as follows.

$$
\frac{1}{f_{\mathrm{CO}_{2}}}=\frac{1}{f_{\mathrm{u}}}+1
$$

From the combination of eq 18 and 19

$$
\frac{1}{f_{\mathrm{u}}}=\frac{k_{\mathrm{NN}}}{K_{\mathrm{s}} k_{\mathrm{NC}}\left[\mathrm{CO}_{2}\right]_{0}[\mathrm{~N}]_{0}}+1
$$

This equation, according to mechanism I, differs from eq 17 according to mechanism II, and experimental results, as indicated in Figure 6, agree not with eq 20 , but with eq 17 . These results are consistent with the proposed mechanism that this copolymerization proceeds via an equimolar complex of two monomers.

Acknowledgement. The authors are indebted to Mr. Hiroshi Hatta for skilled technical assistance throughout this work, to $\mathrm{Mr}$. Tsukasa Kagiya (Takasaki Radiation Chemistry Establishment, Japan Atomic Energy Research Institute) for ultraviolet analysis, and to Mr. Masatsune Kondo (Central Research Institute, Sumitomo Chemical Industries Co., Ltd.) for thermogravimetric analysis.

\section{REFERENCES}

1. S. Inoue, H. Koinuma, and T. Tsuruta, $J$. Polym. Sci., Part B, 7, 287 (1969).

2. T. Kagiya and K. Narita, Bull. Chem. Soc. Japan, 42, 3221 (1969).

3. H. W. Heine, B. L. Kapur, and C.S. Match, J. Amer. Chem. Soc., 76, 1173 (1954).

4. R. Tsuzuki, K. Ichikawa, and H. Kose, J. Org. Chem., 25, 1009 (1960).

5. T. Mukaiyama, T. Fujisawa, H. Nohira, and T. Hyugaji, Bull. Chem. Soc. Japan, 35, 687 (1962).

6. T. Mukaiyama, T. Fujisawa, H. Nohira, and T. Hyugaji, J. Org. Chem., 27, 3337 (1962).

7. T. Kagiya, T. Kondo, and K. Fukui, Bull. Chem. Soc. Japan, 41, 2473 (1968). 